\title{
A Secure Parking Reservation System Using GSM Technology
}

\author{
Yusnita Rahayu and Fariza N. Mustapa
}

\begin{abstract}
In this paper, a secure parking reservation system using Global System for Mobile communications (GSM) technology has been performed. It helps the drivers from facing the problem that always occurs at the car park, such as time being wasted in searching for the available parking spaces and keep on circling the parking area until they found an empty parking spot. This problem usually occurs in urban areas, where number of vehicles are higher as compared to the availability of parking spaces. In this proposed system there are two modules have been developed such as parking lot monitoring and security reservation modules. For the parking lot monitoring module, the layout animation is used to display the parking lot status. In security reservation module, the users need to send SMS to reserve the parking lot and use the password provided to enter and exit the parking lot. Our main contribution is the system has more security than other previous research with the used of password to enter and exit.
\end{abstract}

Index Terms-Parking security, GSM, SMS, parking reservation.

\section{INTRODUCTION}

As reported in [1], the increasing of vehicle theft increased and getting worried by the vehicle users. One of the main reasons of this situation is the users facing a hard way to find the secure parking lot for their vehicle. Security is the main issue that lacks in many of the parking areas [2]. Many improvements for vehicle security at the parking lot have been done with the growing of the technology today.

There are many methods introduced by researchers to solve this problem. In [3], the authors used SMS technology as a communication code and get to online in order to reserve the parking lot. The weakness of this project is the users need to online first before get reserve the parking lot. It will take time and trouble for some users that not have the internet facilities. Therefore, in this paper we proposed the GSM technology to get the conformation code to overcome this weakness. By using this technology, the process of reservation can be more easy and simple.

In [4], the authors also proposed the SMS technology to get password from the GSM to reserve the parking lot. In the exit process, the users need to flow the exit path and the barrier gate automatically open due to the presence of vehicle by sensor detection. This system is lack of security for the exit process because the car can easily exit through the sensor detection. It is easy for the unauthorized person to take any car out. In this paper, another approach will be applied by using password in and out. The users will receive

Manuscript received January 14, 2013; revised April 15, 2013.

The authors are with the Department of Electrical \& Electronics Engineering, Universiti Malaysia Pahang, Pekan 26600, Malaysia (e-mail: vannebula2001@yahoo.com, fariza_norbaya@yahoo.com). the password together with location of parking lot reserved. Thus, our project has more security for the users and their vehicles. This project is the continuous from our previous project [5] as a complement to complete an intelligent parking system.

\section{APPROACH \& METHODS}

For this project, we mainly focus on designing a smart and secure parking reservation system that allow drivers to reserve and park their vehicle in safety condition. This process divided into two parts which are security reservation module and parking lot monitoring module. Fig. 1 shows the security reservation module and Fig. 2 shows parking lot monitoring module. The detail for each module will be described below.

\section{A. Security Reservation Module}

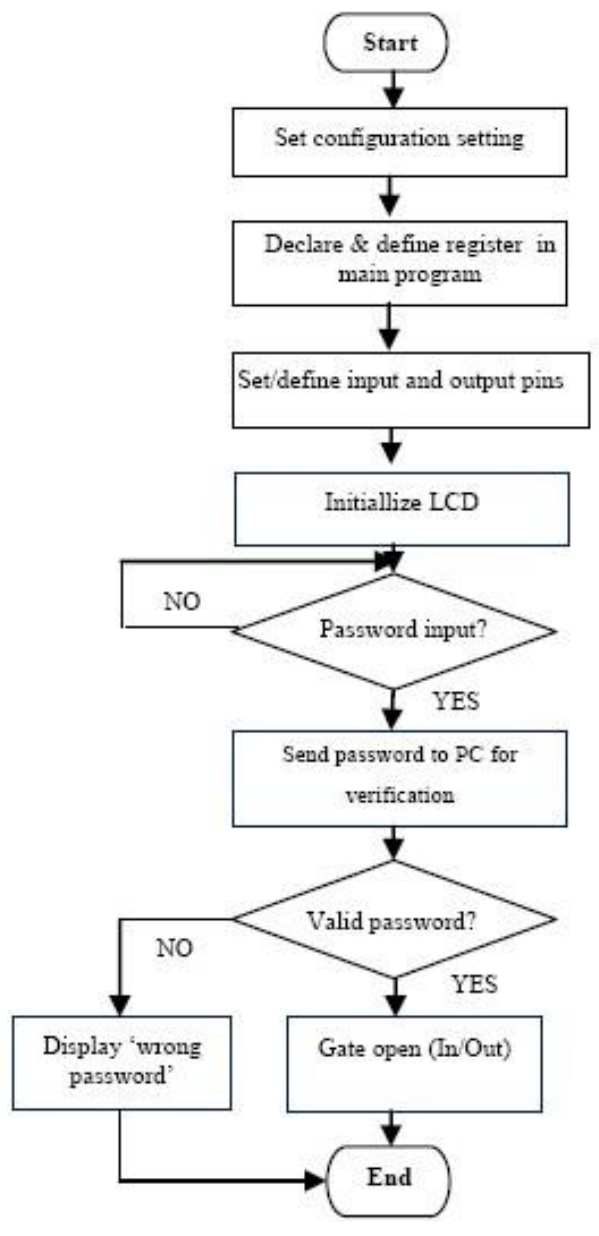

Fig. 1. Security reservation module

Fig. 1 shows the flowchart of reservation module. The SMS reservations valid for all the GSM mobile phone users. In [6], the authors reported the number of SMS usage in 
2008 is about 16.8 million and it will increase steadily for every year. This flowchart involves installing and configuring SMS hardware and software. The main hardware and software are PIC microcontroller and VB. When the users want to reserve the parking lot, they have to send a SMS with the right command for thereservation process to configure the microcontroller. GSM modem is used to send and receive SMS from the users. The LCD initializes and as an interface between microcontroller and the keypad output. The users will receive the status of the availability of parking lot with its location and password. The password will be processed by the PIC microcontroller through the VB for verification process.Then,the users need to enter the password for in/out process. If the users enter the wrong password, the LCD will display "wrong password" and the gate locked.

\section{B. Parking Lot Monitoring Module}

Fig. 2 shows the flowchart of parking lot monitoring module. For initial condition, all the parking lots are set to empty status. When the users successfully request the parking lot, the parking layout will display the reserve status. When the users reach the entrance gate and enter the password, the controller will compared the password entered with the reservation database. If the valid password entered, the gate barrier will be opened and the parking layout will display full status.

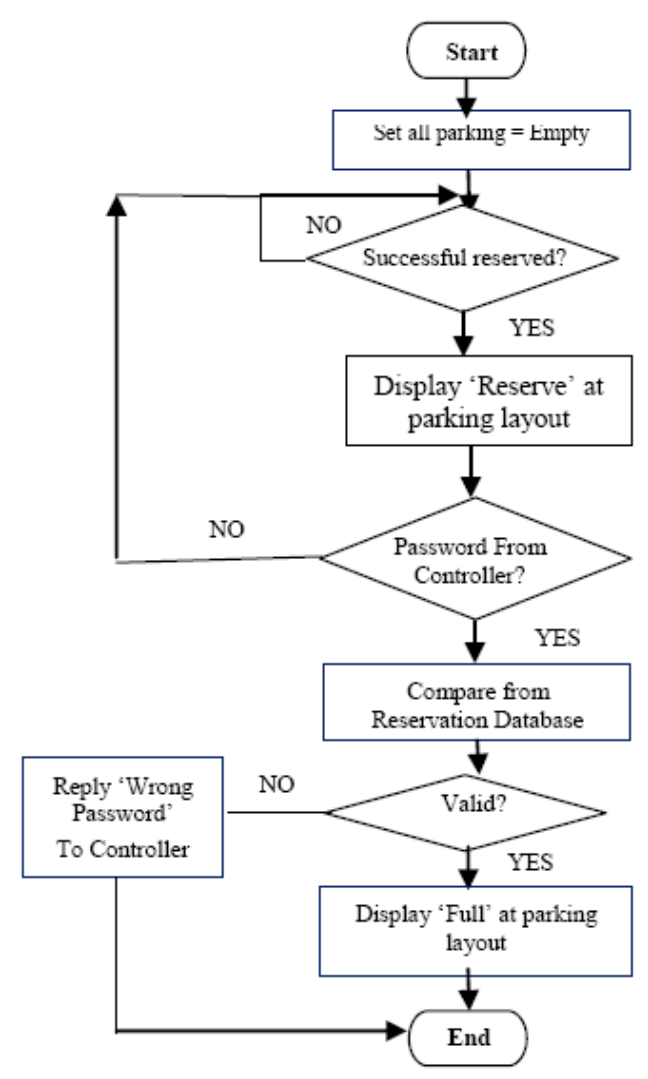

Fig. 2. Parking lot monitoring module.

\section{DeSIGN OVERVIEW}

Fig. 3 illustrates the function block of GSM system consists of GSM modem, PC, Max 232, PIC 16F877, motor driver, keypad and LCD. GUI interface with parking layout animation, database, and SMS processing functionality use the VB application. The details explanation will be discussed below.

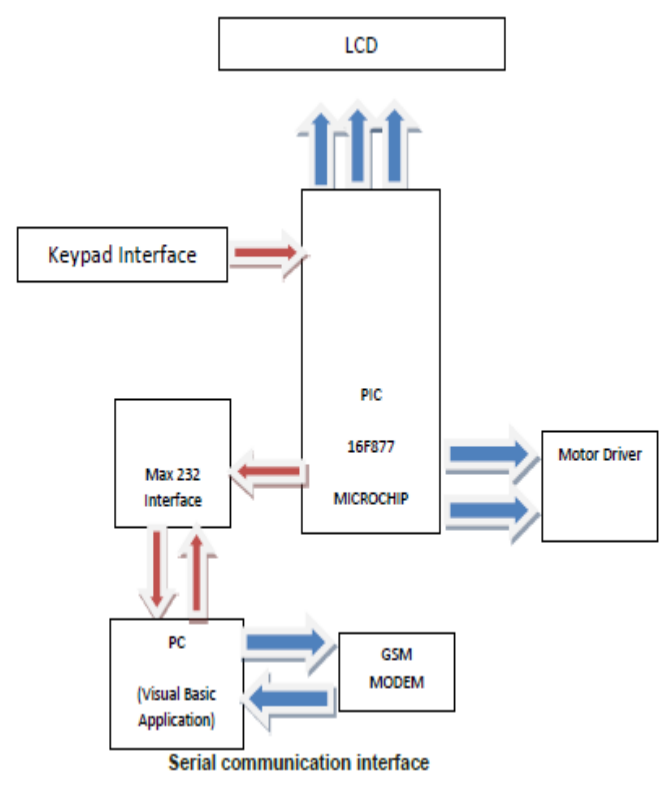

Fig. 3. Function block of GSM system.

\section{A. PIC Microcontroller}

A Peripheral Interface Controller (PIC) microcontroller is a single integrated circuit (IC) which is small enough but containing all the integrated circuits such as CPU, EPROM program memory, RAM memory and an Input/Output interfaces. This PIC16F877 type is used as a main controller for this smart parking reservation system

\section{B. Visual Basic}

Visual Basic (VB) is designed to be relatively easy to learn and use.For this project, this software will be used to create a parking layout animation. This software also be used for database and SMS processing functionality.

\section{C. $L C D$}

The liquid crystal display (LCD) is used as an interface between microcontroller and keypad output. For status display during password entry and display result/reply from the PC. If the users enter the wrong password, the LCD will inform it as "wrong password" and the gate cannot be opened.

\section{Motor Driver}

The motor driver is used to control the barrier gate at parking lot for in and out process. The motor controller only active when receive the right password. This is the security features for this smart parking reservation system.

\section{E. GSM}

Global System for Mobile communications (GSM) is an open, digital cellular technology used for transmitting mobile voice and data services. The communication medium between the users and the hardware modules is the GSM modem via SMS formats.

\section{Result/Evaluation}

In this section, evaluation of a secure parking reservation system by using GSM technology has been performed. The screenshots of the overall process systems are shown in the 
figures below:

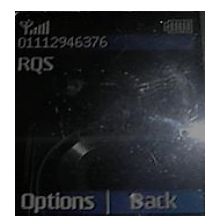

(a)

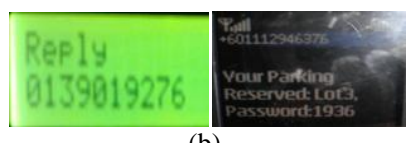

(b)

Fig. 4. (a) Send a request, (b) Reservation cormfirmation parking message.

Fig. 4 (a) shows the message sent by the users to request a parking lot. Fig. 4 (b) illustrates the reservation confirmation parking message. The database will check the status of availability of parking lot before sending the conformation.

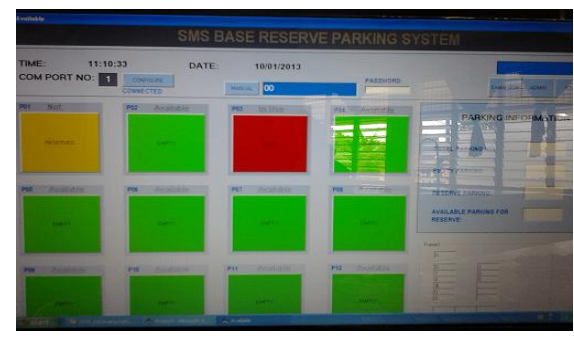

Fig. 5. Reservation layout cormfirmation message.

When the users get the password for the availability parking lot from the database via SMS, the parking layout module will display the reserve mode (yellow). Once the users enter the correct password at the entrance gate, the parking layout module will display full mode (red) to indicate the occupancy of parking lot and the empty parking lot that available to reserve (green) is, as show in Fig. 5.

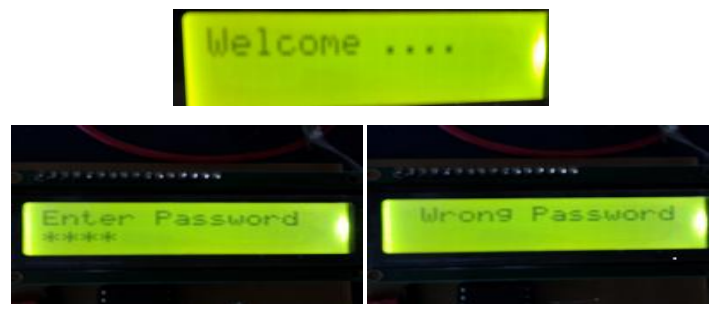

(a)

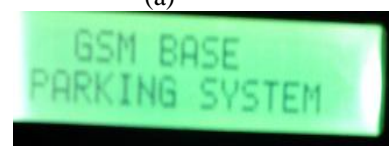

(b)

Fig. 6. (a) LCD display for password mode, (b) LCD display in enter/exit gate.

Fig. 6 (a) shows the LCD display for the password mode and Fig. 6 (b) show for a standby mode at entry and at the end point of this process.

\section{CONCLUSION}

In this paper, a secure parking reservation system using GSM technology has been developed. The security feature of the system is the usage of the password requirements upon enter and exit the parking lot. It comprises of two modules which are parking lot monitoring and security reservation modules. From the result obtained, the proposed parking reservation system by using GSM technology can enhance the safety of the vehicle at parking lot and improve the parking management performance, thus reduce the time of traffic volume searching for parking.

\section{ACKNOWLEDGMENT}

This project is supported by University Malaysia Pahang under grant RDU 110135. The authors would like to thank Research and Innovation Department of University Malaysia Pahang for the financial support.

\section{REFERENCES}

[1] One-Stolen-Every-24-Minutes-In-Malaysia. [Online]. Available: http://www.wanita.net.my/home/index.php

[2] A. Sayeeraman and P. S. Ramesh. (March 2012). Zigbee and GSM based secure vehicle parking management and reservation system. journal of theoretical and applied information technology. [Online]. Available:

http://www.jatit.org/volumes/Vol37No2/thirtyseventh_volume_2_201 2.php

[3] H. W. Wang and W. B. He, "A reservation based smart parking system," in Proc. 2011 Computer Communications Workshops (INFOCOM WKSHPS), pp. 690-695.

[4] N. H. H. M. Hanif, M. H. Badiozaman, and H. Daud, "Smart parking reservation system using short message services," in Proc. the International Conference on Intelligent and Advanced Systems, ICIAS 2010, pp. 1-5

[5] R. Yusnita, F. Norbaya, and N. Basharuddin, "Intelligent parking space detection system based on image processing," The International Journal of Innovation, Management and Technology, vol. 3, no. 3, pp 232-235, June 2012.

[6] Communications and Multimedia Selected Facts and Figures 2008, Malaysian Communications and Multimedia Commission, Cyberjaya 2008, pp. 15-38.

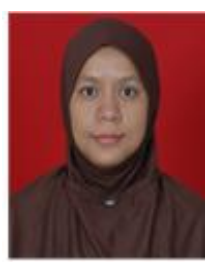

Yusnita Rahayu Naumar was born in Pekanbaru, Indonesia, November $4^{\text {th }}, 1975$. Y.R Naumar graduated Bachelor of Engineering (B.Eng) in telecommunication field from Institute Science and Technology National (ISTN), Jakarta, Indonesia in 1999, and finished Master of Engineering (M.Eng) and Doctor of Philosophy (PhD) in wireless communication area from Universiti Teknologi Malaysia (UTM), Johor Bahru, Malaysia in 2003 and 2008, respectively.

Currently, she is a Senior Lecturer and a Researcher at Faculty of Electrical and Electronics Engineering of Universiti Malaysia Pahang (UMP), Malaysia. After her first degree, she worked for ISTN as an Assistant Laboratories in 1999 - 2000. She has managed and conducted three laboratories such as computer lab, electronics lab and Programmable Logic Controller (PLC) lab. During her M.Eng study, she was also actively involved some research projects under Wireless Communication Centre (WCC) of Universiti Teknologi Malaysia that were relating to wireless communication system. She has published more than 30 papers for referred national and international conference, 5 book chapters, 2 referred invited journals. Now, she is a Project Leader for the current short term project grant under Universiti Malaysia Pahang.

Dr. Y.R Naumar is also active as reviewer and technical program committee for various journals and conferences. She is a senior member of IEEE, member of IEEE antenna \& propagation society. She is also member of AMTA, IEEE Standard Association and Institute Engineer of Indonesia. Her interest areas are such as radio transceiver design, antenna for wireless communication application, sensor network, control, solar and monitoring system.

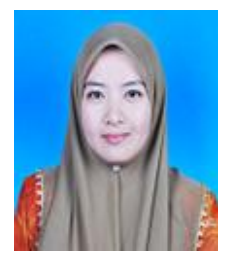

Fariza Norbaya Mustapa was born in Terengganu, Malaysia, October $2^{\text {nd }}, 1984$. F.N Mustapa graduated Bachelor of Engineering (B.Eng) in telecommunications field from University Malaysia Perlis, Malaysia in 2011. Currently, she is a postgraduate candidate with Faculty of Electrical and Electronics Engineering of Universiti Malaysia Pahang (UMP), Malaysia. 